Pseudomonas aeruginosa, a pathogen that mainly infects hospital patients. Several sugars produced by $P$. aeruginosa form components of its biofilm matrix, and the team identified two glycoside hydrolase enzymes that target and break down two of these sugars. When added to biofilms of clinical and environmental strains of the bacterium in culture, the enzymes degraded the films by $58 \%$ to $94 \%$. They also inhibited biofilm formation for up to 72 hours and, when combined with an antibiotic, reduced bacterial growth by more than the antibiotic alone.

The authors say they have begun tests in animals to study the enzymes' therapeutic potential.

Sci. Adv. 2, e1501632 (2016)

\title{
EVOLUTION \\ Songs drove sunbird evolution
}

In two bird populations, differences in social traits, rather than just physical ones, are enough to generate new species.

Jay McEntee at the University of California, Berkeley, and his colleagues set out to understand how two species of sunbird that live side by side in East Africa, Nectarinia moreaui (pictured) and Nectarinia fuelleborni, evolved into separate species. The team compared the animals' genetics, physical traits, habitat preferences and songs, which are used by males to compete for territory and possibly for mates. They found that the species are physically similar and prefer the same types of food and habitat. However, the birds' songs differ in

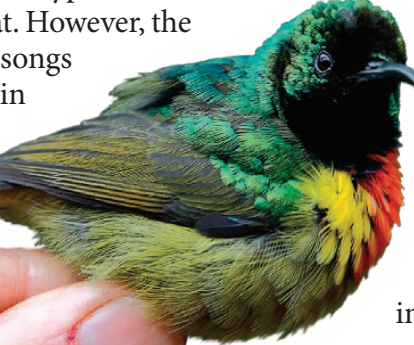

duration and structure.

Genetic predispositions for different songs may have split the two species even though the birds share common habitats, the authors say. Evolution http://doi.org/bhpx (2016)

\section{PALAEONTOLOGY}

\section{Ancient origins of multicellular life}

Large, multicellular life forms may have appeared on Earth one billion years earlier than was previously thought.

Macroscopic multicellular life had been dated to around 600 million years ago, but new fossils suggest that centimetres-long multicellular organisms existed as early as 1.56 billion years ago. Maoyan Zhu at the Chinese Academy of Sciences in Nanjing and his colleagues report the discovery of well-preserved fossils from northern China showing organisms up to 30 centimetres in length. The creatures' cells measure 6-18 micrometres in diameter and are closely packed. From comparisons with modern organisms, the authors suggest that the fossils were probably photosynthetic eukaryotes similar to modern algae.

The finding challenges the idea that this period of evolution was relatively uneventful, the authors say. Nature Commun. 7, 11500 (2016)

$$
\text { REGENERATION }
$$

\section{Muscle stem cells show dual purpose}

Researchers have observed stem cells in the muscles of live zebrafish dividing to produce both more stem cells and cells that repair injury.

This 'asymmetric division' of stem cells has been observed in culture. To find evidence in living organisms, Peter Currie and his colleagues at Monash University in Clayton, Australia, engineered zebrafish larvae

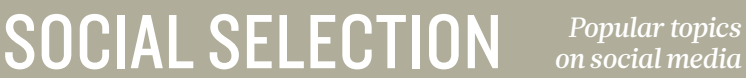

\section{Scientific sceptics hit back}

Champions of rational, evidence-based thinking are seething after a public rebuke at one of their own conferences. Speaking on 15 May at the Northeast Conference on Science and Skepticism in New York, science journalist John Horgan said that sceptics - researchers and other people who promote the scientific method - spend too much time debunking 'soft' targets such as homeopathy when they should be going after tougher, 'hard' issues, such as whether regular mammograms save lives. Whereas some attendees welcomed the message, conference co-organizer Steven Novella, a neurologist at Yale University School of Medicine in New Haven, Connecticut, argued on his NeuroLogica blog that sceptics have been grappling with both hard and soft targets for years: "We are already miles past the superficial

$\rightarrow$ NATURE.COM

For more on popular papers: go.nature.com/eaamst framing that Horgan gives." Horgan said that he had an "impressionistic view" of the topics that were important to sceptics but that he hadn't taken a full survey. to produce fluorescent proteins in their muscle cells, and monitored them over time using microscopes. They found that after an injury, stem cells infiltrated the wound and divided to produce two distinct cell types: one went on to form new muscle tissue, while the other had high levels of $c$ met, a marker specific to stem cells in muscle and other tissues.

This system of cell renewal could be a feature of vertebrates in general, the team says.

Science http://dx.doi.org/ 10.1126/science.aad9969 (2016)

\section{ROBOTICS}

\section{Robot hangs with electrostatic force}

A lightweight flying robot can attach to and take off from objects in the environment by controlling electrostatic adhesion.

Moritz Graule and Robert Wood at Harvard University in Cambridge, Massachusetts, and their colleagues designed the insect-sized robot (pictured) to suspend from overhangs, such as those on trees and

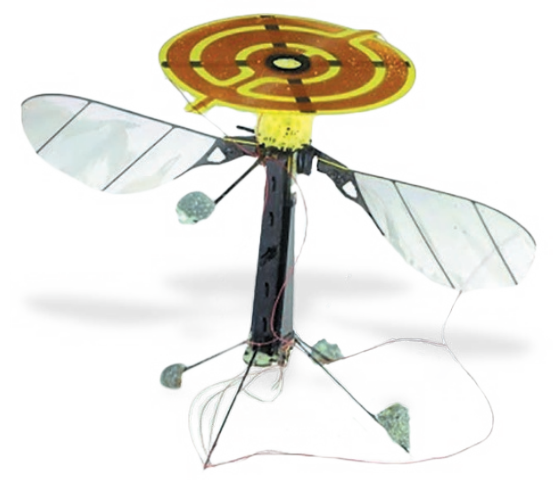

buildings. The top of the device has a patch containing copper electrodes. Switching on the voltage between the electrodes induces opposing charges on the surface of a nearby target, generating an electrostatic attraction. Switching off the voltage releases the robot. The device can cling to a variety of surfaces, including glass, wood and leaves.

The authors suggest that this mechanism could help small aerial robots to conserve their energy and stay aloft for longer periods.

Science 352, 978-982 (2016)

\section{$\rightarrow$ NATURE,COM}

For the latest research published by Naturevisit:

www.nature.com/latestresearch 